\title{
Identification and characterization of aging products in the glyoxal/ammonium sulfate system - implications for light-absorbing material in atmospheric aerosols
}

\author{
C. J. Kampf, R. Jakob, and T. Hoffmann \\ Institute for Inorganic and Analytical Chemistry, Johannes Gutenberg-University Mainz, 55128 Mainz, Germany \\ Correspondence to: T. Hoffmann (hoffmant@uni-mainz.de)
}

Received: 7 February 2012 - Published in Atmos. Chem. Phys. Discuss.: 29 February 2012

Revised: 13 July 2012 - Accepted: 16 July 2012 - Published: 23 July 2012

\begin{abstract}
In this study we report the identification of bicyclic imidazoles in aqueous aerosol mimics using HPLCESI-MS/MS. 2,2'-Biimidazole was identified to be a major contributor to the $280 \mathrm{~nm}$ absorbance band observed in mixtures of glyoxal and ammonium sulfate, despite the fact that its production rate is two orders of magnitude lower than the previously reported production rates of imidazole or imidazole-2-carboxaldehyde. The molar absorptivity of 2,2' biimidazole was determined to be $(36690 \pm 998) \mathrm{M}^{-1} \mathrm{~cm}^{-1}$. This demonstrates the necessity of molecular product identification at trace levels to enable a better understanding of relevant absorbing species. Additionally, the formation of lower polarity products including formamides of imidazoles is proposed. The role of imidazoles and other light-absorbing species in the formation of SOA and optical properties of SOA is discussed and potentially interesting fields for future investigations are outlined.
\end{abstract}

\section{Introduction}

Atmospheric aerosols impact global and regional climate, air quality and human health (Seinfeld and Pandis, 2006). Fine mode atmospheric aerosols (submicron particles) are comprised of organic aerosols (OA) as a major fraction (Zhang et al., 2007). The organic matter in those submicron particles is mostly secondary in nature (Jimenez et al., 2009). Over the past years the perception that secondary organic aerosols (SOA) are formed only by gas to particle conversion of low volatility products from atmospheric oxidation processes of volatile organic compounds (VOCs) (Pankow 1994; Odum et al., 1996) has changed and now also involves heterogeneous chemistry and particle phase chemistry of more volatile oxidation products (Hallquist et al., 2009; Lim et al., 2010; Ervens et al., 2011). Prominent examples of such compounds are the two simplest and most abundant $\alpha$-dicarbonyl compounds glyoxal (Gly) and methylglyoxal (Mgly), which remain at least partly in the particle phase through a number of possible reaction pathways in the condensed phase. Briefly, these pathways include self-oligomerization (Kalberer et al., 2004; Hastings et al., 2005; Liggio et al., 2005a,b; Loeffler et al, 2006; Zhao et al., 2006), aldol condensation (Schwier et al., 2010; Sareen et al., 2010; Yasmeen et al., 2010), formation of nitrogen-containing compounds and nitrogencontaining oligomers (De Haan et al., 2009a,b, 2011; Noziere et al., 2009; Galloway et al., 2009; Shapiro et al., 2009; Yu et al., 2011; Kua et al., 2011) as well as organosulfates (Liggio et al., 2005a; Surratt et al., 2007, 2008; Galloway et al., 2009). Furthermore, oxidation of Gly and Mgly in the particle phase by $\mathrm{OH}$ radicals resulting in the formation of lower volatility carboxylic acids (e.g. oxalic acid or pyruvic acid) (Carlton et al., 2007; Tan et al., 2009, 2010; Lim et al., 2010; Altieri et al., 2008) are also discussed as sources of SOA from small $\alpha$-dicarbonyl compounds.

Another important aspect of aqueous phase chemistry besides SOA formation is the potential influence of the respective products on aerosol properties, e.g. optical properties. Bones et al. (2010) report the formation of strong absorbers and fluorophores in mixtures of limonene- $\mathrm{O}_{3} \mathrm{SOA}$ and ammonium sulfate or amino acids. In recent studies the formation of light-absorbing material in aqueous aerosol mimics containing $\alpha$-dicarbonyl compounds and ammonium 
sulfate was observed and nitrogen-containing compounds were identified as products in bulk and chamber experiments (Shapiro et al., 2009; Galloway et al., 2009; De Haan et al., 2009, 2011; Yu et al., 2011; Trainic et al., 2011, 2012). Lightabsorbing material was formed when glyoxal was introduced into ammonium ion containing solutions, i.e. ammonium sulfate (AS) or ammonium nitrate solutions, while no such lightabsorbing species were observed when glyoxal was introduced into salt solutions without ammonium ions, i.e. sodium sulfate or sodium chloride. Imidazoles were identified as major products from the reactions of $\alpha$-dicarbonyl compounds and ammonium ions or primary amines, e.g. methylamine and amino acids (De Haan et al., 2009a,b, 2011; Yu et al., 2011; Trainic et al., 2012). Yu et al. (2011) identified imidazole and imidazole-2-carboxaldehyde, which was identified as a product in the glyoxal/ammonium sulfate system (Gly/AS system) earlier by Galloway et al. (2009), as major carriers of the absorption observed in the Gly/AS system and confirmed nitrogen-containing compounds to be responsible for the light absorption in this system by studying solutions of glyoxal and ammonium, methylamine, and dimethylamine salts. Additionally, they experimentally confirmed the formation of formic acid, which has been proposed to be a side product in imidazole formation from glyoxal and amino acids by De Haan et al. (2009a), in one of two major pathways of the reaction of glyoxal with ammonia or primary amines. Thus the $\mathrm{pH}$ value in solution was found to decrease over time and consequently the rate of the formation of imidazoles was observed to decrease. However, Yu et al. were not able to explain the observed absorbance in Gly/AS mixtures completely. Very recently, Trainic et al. (2011) reported the formation of a particle phase product absorbing at $\lambda=290 \mathrm{~nm}$ in ammonium sulfate seed aerosols exposed to gas phase glyoxal for a wide range of RH values. They also report a higher ratio of $\mathrm{C}-\mathrm{N}$ oligomers to glyoxal oligomers in AS/glycine (100:1) seed particles, likely due to an acid catalyzed imine formation from glycine and glyoxal (Trainic et al., 2012).

The purpose of this paper is to further complete the understanding of the product spectrum of the reaction of glyoxal and ammonium sulfate in aqueous aerosol mimics through the identification of several new imidazole products and kinetic investigations. Therefore, we use high performance liquid chromatography coupled with UV-Vis and mass spectrometric detection (Electrospray Ionization Ion Trap Mass Spectrometry, ESI-IT-MS). The time resolved chromatographic separation of the reaction mixture, combined with the use of reference compounds, is a powerful tool for the assignment and structural identification of reaction products in a dynamic aqueous phase reaction like the Gly/AS system. Additionally, we report the formation of species absorbing at near visible wavelengths, which are of low polarity and relatively high molecular weight, and discuss the implications for light-absorbing material in SOA from glyoxal.

\section{Experimental}

\subsection{Chemicals and materials}

Ammonium sulfate $(>99.5 \%)$, ammonium hydroxide solution $(28 \%)$, formic acid (>99\%), 1H-imidazole (>99\%) and glyoxal (40\% wt. solution) were obtained from Acros Organics, ammonium nitrate (>99\%) from Fluka, hydrochloric acid $(30 \%)$ from Merck and 1H-imidazole-2carbaldehyde ( $>99.5 \%$ ) from Maybridge. Ultrapure water was obtained using a MilliQ water system (Millipore, USA). HPLC gradient grade acetonitrile was obtained from VWR.

\subsection{Aqueous aerosol mimics}

In order to achieve the best possible approximation of aqueous atmospheric aerosols with batch experiments and to be able to compare the results of this study with literature data (Shapiro et al., 2009; Noziere et al., 2009; Yu et al., 2011) $3 \mathrm{M}$ solutions of $\left(\mathrm{NH}_{4}\right)_{2} \mathrm{SO}_{4}$ (ammonium sulfate, AS) were prepared containing initial glyoxal concentrations ranging from $0.01 \mathrm{M}$ to $1.5 \mathrm{M}$. Sample solutions were prepared in batches of $10 \mathrm{ml}$. All samples read $\mathrm{pH}=4( \pm 1)$, achieving a $\mathrm{pH}$ relevant to tropospheric aerosols. All mixtures were stored in brown glass auto sampler vials until analysis without being shaken or stirred. The brown glass auto sampler vials are expected to provide a good shielding from UV, thus the samples were not otherwise protected from light. A list of selected experiments is available in the Supplement (Table S1).

\subsection{Reference compounds}

2-(1H-imidazol-2-yl-)-1H-imidazole (2,2'-bisimidazole, 2,2'-biimidazole, BI) was synthesized using a modification of a method of Debus (1858) and Fieselmann et al. (1978) by Mao et al. (2003), who substituted the ammonia gas with concentrated $\mathrm{NH}_{4} \mathrm{OH}(28-30 \%)$ solution. HPLC-DAD-ESIMS showed that the product was pure. $1 \mathrm{H}$-imidazole (IM) and 1H-imidazole-2-carboxaldehyde (IC) were commercially available in $>99.5 \%$ purity. $0.02 \mathrm{M}$ solutions of IM, IC and BI were prepared by dissolving the solids in $10 \mathrm{ml}$ ultrapure water acidified with $20 \mu \mathrm{l}$ of $1 \mathrm{M}$ hydrochloric acid. Absorption spectra of IM, IC and BI are available in the Supplement (Figs. S16-S18). To characterize the glyoxal substituted imidazoles, samples were prepared to be $0.02 \mathrm{M}$ with respect to Gly and IM, IC or BI, respectively. These samples were analyzed immediately after preparation and showed the respective educts as well as the $\mathrm{N}$-glyoxal substituted imidazoles.

\subsection{HPLC-DAD-ESI-MS/MS measurements}

All samples were analyzed by HPLC-DAD-ESI-MS measurements using an HCT-Plus ion trap mass spectrometer (Bruker Daltonics GmbH, Bremen, Germany) equipped with 
an HPLC-System (Agilent 1100 series, auto sampler, gradient pump, degasser and diode array detector (DAD), Agilent Technologies GmbH, Germany) and an Atlantis T3 $150 \mathrm{~mm}$ $\times 2.0 \mathrm{~mm}$ column with $3 \mu \mathrm{m}$ particle size (Waters, Germany). The eluents were ultrapure water with $0.1 \%$ formic acid and $2 \%$ acetonitrile (eluent $\mathrm{A}$ ), and acetonitrile with $2 \%$ water (eluent B). The gradient of the mobile phase, with a flow of $0.2 \mathrm{ml} \mathrm{min}^{-1}$, was chosen as follows: Starting with $1 \% \mathrm{~B}$, gradient to $100 \% \mathrm{~B}$ in $30 \mathrm{~min}$, isocratic for $5 \mathrm{~min}$ and gradient to $1 \% \mathrm{~B}$ in $5 \mathrm{~min}$. The column was equilibrated at $1 \% \mathrm{~B}$ for $20 \mathrm{~min}$. The HPLC system was connected to the MS via a DAD equipped with a $500 \mathrm{~nL}$ flow cell. The electrospray ion source of the MS was operated using the following setup: nebulizer pressure $2200 \mathrm{mbar}$, dry gas flow $91 \mathrm{~min}^{-1}$, dry gas temperature $300^{\circ} \mathrm{C}$ and spray voltage $4500 \mathrm{~V}$.

\section{Results and discussion}

\subsection{Imidazole formation in the glyoxal/ammonium sulfate system}

The reaction of glyoxal with ammonia, which is present in ammonium sulfate solutions in concentrations dependent on the $\mathrm{pH}$ value of the solution, yields a variety of different imidazoles. Figure 1 depicts proposed pathways for the formation of imidazoles in the Gly/AS system as discussed by $\mathrm{Yu}$ et al. (2011), who concluded the formation of $1 \mathrm{H}$-imidazole (IM), hydroxyl(1H-imidazol-1-yl)acetaldehyde or N-glyoxal substituted $1 \mathrm{H}$-imidazole (GI), its hydrated form (HGI), 1Himidazole-2-carbaldehyde (IC) and its hydrated form (HIC) from NMR studies on the Gly/AS system. In addition to these products we propose the formation of 2-(1H-imidazol2-yl)-1H-imidazole (or 2,2'-bisimidazole, 2,2'-biimidazole, BI) from further reactions of IC with ammonia. This product is already known in the literature (Mao et al., 2003; Fieselmann et al., 1978) and its formation from the reaction of glyoxal with an ammonium salt has also been described in US patent 6713631 (Cho et al., 2003). Here we report the formation of BI under atmospherically relevant conditions, i.e. not basic $\mathrm{pH}$. We believe BI is a major contributor to lightabsorbing material formed in the Gly/AS system although it is only produced in small amounts as will be discussed in the following Sect. 3.2.

The HPLC-DAD-ESI-MS/MS analysis of Gly/AS mixtures at different times after mixing reveals two main features in their temporal product evolution. The first feature is observed in the chromatograms between 2.0 and $2.5 \mathrm{~min}$ retention time. It is accompanied by an increase in UV absorption at 210 and $280 \mathrm{~nm}$. A typical mass spectrum of this feature from a solution of $1.5 \mathrm{M}$ Gly in $3 \mathrm{M}$ AS is shown in Fig. 2 (69.7 h after mixing, retention time of $2.3 \mathrm{~min}$ ). All mono-imidazole products described in Fig. 1 are visible at this point except IC and GI, which likely are completely hydrated under the analytical conditions applied here. This includes $m / z \quad 69=1 \mathrm{H}$-imidazole (IM), $m / z \quad 115=$ hydrated 1H-imidazole-2-carbaldehyde (HIC), $m / z \quad 145=$ hydrated $\mathrm{N}$-glyoxal substituted $1 \mathrm{H}$-imidazole $(\mathrm{HGI}), \mathrm{m} / z \quad 173=\mathrm{N}-$ glyoxal substituted hydrated $1 \mathrm{H}$-imidazole-2-carbaldehyde (GHIC), $m / z 203$ =hydrated glyoxal dimer substituted imidazole (HGGI). The second feature is visible at around $3.5 \mathrm{~min}$ retention time, where an increase in one specific UV signal at $280 \mathrm{~nm}$ absorption is observed. Fig. 3 shows a typical mass spectrum of this feature from a solution of $0.01 \mathrm{M}$ Gly in $3 \mathrm{M}$ AS $(23.46 \mathrm{~h}$ after mixing, retention time of $3.4 \mathrm{~min}$ ). The two prominent signals correspond to BI $(m / z$ 135) and its glyoxal substituted analog GBI $(m / z$ 193). The identity of these products was confirmed through reference compounds. A detailed characterization in terms of chromatograms, MS and MS/MS spectra is available in the Supplement (Figs. S1-S9). Retention times, protonated ion masses and abundant fragments for the observed products are listed in Table 1. Control experiments (Experiments 911 in Table S1 in the Supplement) were conducted to obtain chromatograms of water, ammonium sulfate and glyoxal backgrounds. No imidazole signals were observed in these chromatograms.

\subsection{Characterization and kinetic investigations of $\mathrm{BI}$ in the Gly/AS system}

All previous studies on the formation of light-absorbing material in the Gly/AS system involving UV-Vis analysis observed an increasing absorption at around $280 \mathrm{~nm}$ with increasing time after mixing. Yu et al. (2011) were able to determine IC as one carrier of this absorption band and quantified its contribution. They concluded that additional unknown absorbing species must be present in the mixture to explain the actual absorbance at this wavelength. They calculated a lower limit for the molar absorptivity of $3100 \mathrm{M}^{-1} \mathrm{~cm}^{-1}$ (in water) for a single compound contributing to this absorption band to explain the remaining absorbance. Their calculation was based on the assumption that no unidentified signals at concentrations higher than $0.1 \mathrm{mM}$ were observed at $190.5 \mathrm{~min}$ after mixing of a 3.3 M AS/0.17 M Gly solution in their NMR spectra. After calibration of the HPLC-DAD-ESI-MS system with the synthesized standard we were able to determine the molar absorptivity of BI in water at $280 \mathrm{~nm}$ to be (36 690 \pm 998$) \mathrm{M}^{-1} \mathrm{~cm}^{-1}$ (see page 7 of the Supplement for more details). BI therefore seems to be a major contributor to the $280 \mathrm{~nm}$ absorption band observed in the recent studies (Shapiro et al., 2009; Noziere et al., 2009; Yu et al., 2011). At a comparable time (176 min) after mixing of a $3 \mathrm{M} \mathrm{AS} / 0.3$ M Gly solution we found a BI concentration of $0.013 \mathrm{mM}$, supporting the calculations of Yu et al. (2011). This clearly demonstrates the importance of the molecular identification of products in the investigated aerosol mimics at trace levels for a better understanding of the absorbance of the reaction mixtures. BI is not a major product of these reactions, 
Table 1. HPLC-ESI-MS/MS characterization of imidazole products in the Gly/AS system. Most abundant fragment ions are written in bold.

\begin{tabular}{|c|c|c|c|c|c|}
\hline $\begin{array}{c}\text { Product } \\
\text { abbreviation }\end{array}$ & Structure & Sum formula & $\begin{array}{c}m / z \\
\text { of }[\mathrm{M}+\mathrm{H}]^{+}\end{array}$ & $\begin{array}{c}\mathrm{m} / \mathrm{z} \text { of } \\
\text { fragments }\end{array}$ & $\begin{array}{l}\text { Retention } \\
\text { time/min }\end{array}$ \\
\hline I & 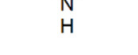 & $\mathrm{C}_{3} \mathrm{H}_{4} \mathrm{~N}_{2}$ & 69.1 & - & 2.2 \\
\hline HGI & $\mathrm{OH}$ & $\mathrm{C}_{5} \mathrm{H}_{8} \mathrm{O}_{3} \mathrm{~N}_{2}$ & 145.1 & 69.1 & 2.3 \\
\hline HGGI & & $\mathrm{C}_{7} \mathrm{H}_{10} \mathrm{O}_{5} \mathrm{~N}_{2}$ & 203.0 & 185.0, 69.1 & 2.4 \\
\hline IC & & $\mathrm{C}_{4} \mathrm{H}_{4} \mathrm{ON}_{2}$ & 97.1 & 69.1 & 2.3 \\
\hline HIC & & $\mathrm{C}_{4} \mathrm{H}_{6} \mathrm{O}_{2} \mathrm{~N}_{2}$ & 115.1 & 97.1 & 2.2 \\
\hline GHIC & & $\mathrm{C}_{6} \mathrm{H}_{8} \mathrm{O}_{4} \mathrm{~N}_{2}$ & 173.1 & $155.1,115.1,97.1$ & 2.4 \\
\hline HGHIC & $\mathrm{OH}$ & $\mathrm{C}_{6} \mathrm{H}_{10} \mathrm{O}_{5} \mathrm{~N}_{2}$ & 191.1 & no data & 2.4 \\
\hline BI & & $\mathrm{C}_{6} \mathrm{H}_{6} \mathrm{~N}_{4}$ & 135.0 & 108.1, 81.0 & 3.5 \\
\hline GBI & & $\mathrm{C}_{8} \mathrm{H}_{8} \mathrm{O}_{2} \mathrm{~N}_{4}$ & 193.0 & 135.0 & 3.5 \\
\hline
\end{tabular}




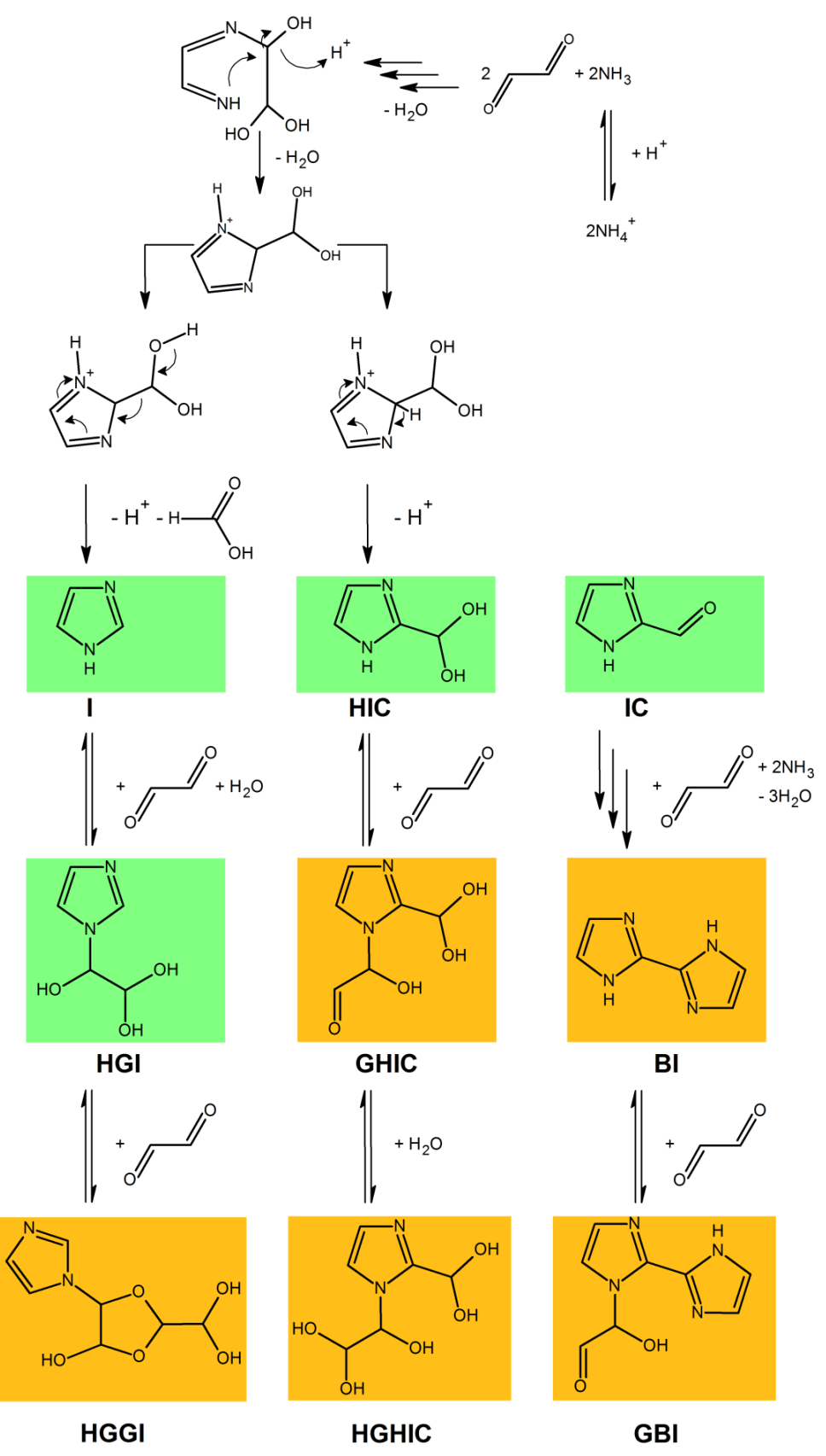

Fig. 1. Proposed reaction pathways for imidazole formation in the glyoxal/ammonium sulfate system are shown. Green colored compounds were previously described in literature (Galloway et al., 2009; Yu et al., 2011); orange colored compounds were identified in this work.

however, due to its high molar absorptivity it is an important contributor to the observed absorbance features. The UV-Vis spectrum of BI can be found in the Supplement (Fig. S16).

The concentration of $\mathrm{BI}$ in the reaction mixtures was monitored over a timescale of one week simulating the estimated mean residence time of sulfur compounds in the troposphere (Seinfeld and Pandis, 2006) as a measure for the mean lifetime of secondary aerosols. Figure 4 shows the con- centrations of $\mathrm{BI}$ as a function of time after mixing of the Gly/AS solution. It was observed that the formation of BI decreases after the first several hours of each experiment. Yu et al. (2011) measured a decreasing $\mathrm{pH}$ value over the course of their experiments using an in situ NMR technique and proposed the formation of formic acid during the formation of IM as the potential reason for this observation. In addition, the removal of ammonia from the corresponding equilibrium 


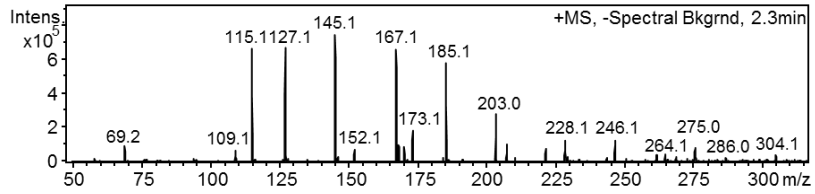

Fig. 2. Typical MS of $1.5 \mathrm{M}$ Gly in $3 \mathrm{M}$ AS at 2.3 min retention time.

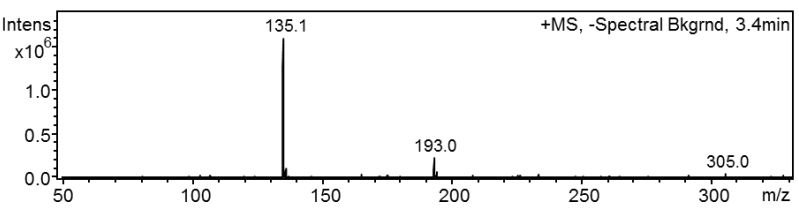

Fig. 3. Typical MS of $0.01 \mathrm{M}$ Gly in $3 \mathrm{M}$ AS at 3.4 min retention time.

reaction (see Eq. 1) by its reactions with glyoxal will influence the $\mathrm{pH}$ (transformation of $\mathrm{NH}_{4}^{+}$to $\mathrm{H}^{+}$). A lower $\mathrm{pH}$ value decreases the amount of available ammonia in solution due to the $\mathrm{pH}$ dependent equilibrium of ammonium ions and ammonia (see Eq. 1).

$\mathrm{NH}_{4}^{+} \rightleftharpoons \mathrm{NH}_{3}+\mathrm{H}^{+}$

$\mathrm{Yu}$ et al. (2011) concluded an exponential dependency between available ammonia and $\mathrm{pH}$ value and report a first order dependency of the production rate of formic $\operatorname{acid} /(\mathrm{IM}+\mathrm{GI})$ and $\mathrm{IC}$ from $\left[\mathrm{H}^{+}\right]$. This dependency applies in a similar way for the production rate of BI, since its formation also involves the nucleophilic attack of ammonia at the carbonyl carbon atom of IC, resulting in a similar temporal behavior.

A stronger decrease of the production rate of $\mathrm{BI}\left(R_{\mathrm{BI}}\right)$ was observed at higher initial glyoxal concentrations, which reflects a stronger decrease of the $\mathrm{pH}$ value as a result of increased IM and formic acid production under these conditions. Thus, to stay in a regime of linear correlation between BI concentration and reaction time only data from the first $\sim 10 \mathrm{~h}$ of the reaction were used to determine the production rates of $\mathrm{BI}$. $R_{\mathrm{BI}}$ ranged from $0.07 \times 10^{-9}$ to $7.19 \times 10^{-9} \mathrm{M} \mathrm{s}^{-1}$ depending linearly on the initial glyoxal concentration (see Table 2). Detailed information on the calculations can be found in the Supplement. Compared to the reported production rates of formic acid, IM and IC in 1.6 M AS/1.5 M Gly solutions (Yu et al., 2011) the initial production rate of $\mathrm{BI}$ is approximately two orders of magnitude lower (3 M AS/1.5 M Gly solution).

Mass spectrometric detection revealed that $11 \%( \pm 1 \%)$ of BI was present as GBI over the timescale investigated for the determination of $R_{\mathrm{BI}}\left([\mathrm{Gly}]_{\text {init }}=0.01 \mathrm{M}\right)$ assuming similar ionization efficiencies for BI and GBI. This indicates a fast equilibrium between BI and GBI depending on the initial Gly concentration. At a given glyoxal concentration

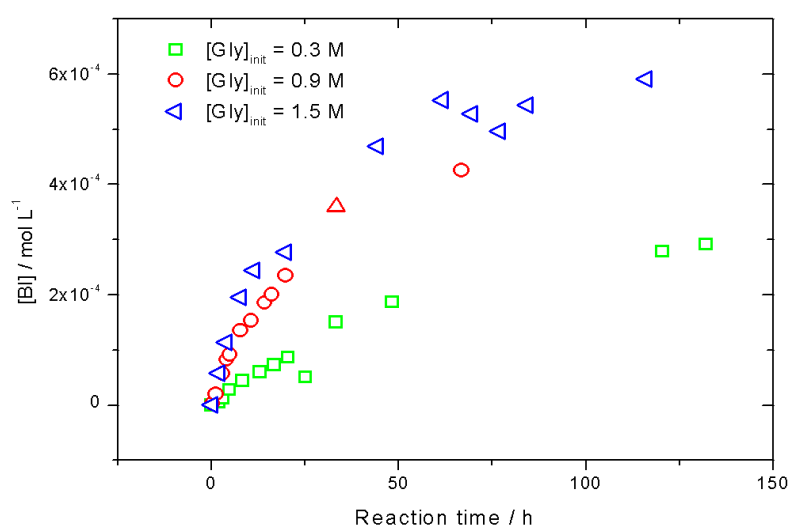

Fig. 4. Concentration of $\mathrm{BI}$ in $3 \mathrm{M}$ AS at different initial glyoxal concentrations is shown as a function of reaction time. Concentrations were determined via $280 \mathrm{~nm}$ absorption band at $3.5 \mathrm{~min}$ retention time using HPLC-DAD.

Table 2. Initial production rates of $\mathrm{BI}\left(R_{\mathrm{BI}}\right)$ depending on initial Gly concentration.

\begin{tabular}{lllll}
\hline$[\mathrm{Gly}]_{\text {init }} / \mathrm{M}$ & 0.01 & 0.3 & 0.9 & 1.5 \\
\hline$R_{\mathrm{BI}} / 10^{-9} \mathrm{M} \mathrm{s}^{-1}$ & $0.074 \pm 0.002$ & $1.58 \pm 0.14$ & $5.0 \pm 0.26$ & $7.19 \pm 0.44$ \\
\hline
\end{tabular}

$[\mathrm{GBI}] /[\mathrm{BI}]$ remains constant for the initial phase of the reaction and correlates linearly with the initial glyoxal concentration (Fig. S13, Supplement). At the highest concentration of $[\mathrm{Gly}]_{\text {init }}=1.5 \mathrm{M} \mathrm{a}[\mathrm{GBI}] /[\mathrm{BI}]$ of 5.17 was observed. However, over the course of the reaction $[\mathrm{GBI}] /[\mathrm{BI}]$ increases slightly with the decreasing $\mathrm{pH}$ value suggesting the equilibrium favors GBI at higher proton concentrations.

\subsection{Characterization of mono-imidazole products}

The molar absorptivities of IM and IC reported by $\mathrm{Yu}$ et al. (2011) are supported by our measurements within the uncertainties of the measurements. We calculated the molar absorptivities in water for: IM at $207 \mathrm{~nm}$ : $4462 \pm 245 \mathrm{M}^{-1} \mathrm{~cm}^{-1}$, IM at $300 \mathrm{~nm}: 18 \pm 2 \mathrm{M}^{-1} \mathrm{~cm}^{-1}$, IC at $213 \mathrm{~nm}$ : $6004 \pm 638 \mathrm{M}^{-1} \mathrm{~cm}^{-1}$, IC at $273 \mathrm{~nm}: 273 \pm 28$ $\mathrm{M}^{-1} \mathrm{~cm}^{-1}$. A minor BI contamination was observed in the IC standard (see Supplement, Fig. S15). However, at higher concentrations, which can be present e.g. in evaporating wet aerosols or cloud droplets, the absorption bands of all imidazoles are subject to a substantial broadening process (see temporal evolution of the product spectra in Fig. S14 in the Supplement).

The effect of suppressed ionization in the ESI source due to the high ammonium sulfate concentrations in the reaction mixtures made it difficult to determine the concentrations of the mono-imidazoles since their retention time was within the ammonium sulfate signal in the chromatograms. 
Additionally, a UV based determination of the concentrations was not possible due to the low chromatographic resolution of the mono-imidazoles hindering a reasonable integration of the respective peaks. Therefore, no kinetic analysis was carried out for these compounds.

\subsection{Characterization of low polarity products}

In addition to the mono- and bicyclic imidazole products of the reaction of glyoxal and ammonia in the investigated Gly/AS mixtures, a number of products with a lower polarity were observed that absorb at wavelengths between 350 $400 \mathrm{~nm}$. Their retention times ranged from 9 to $15 \mathrm{~min}$ as illustrated in Fig. 5.

MS analysis suggests that at least some of these products contain nitrogen atoms since their protonated molecular ions exhibited even $\mathrm{m} / \mathrm{z}$ ratios pointing to an odd number of nitrogen atoms in the molecules. However, products with an even number of nitrogen atoms in the molecule would be observed at odd $m / z$ ratios. Therefore, it cannot be excluded that compounds observed at odd $\mathrm{m} / \mathrm{z}$ ratios during that retention period contain nitrogen atoms. Noziere et al. (2009) proposed the oligomerization of the iminium intermediates after the nucleophilic attack of ammonia at the carbonyl C-atom as a potential pathway for the formation of higher molecular weight compounds other than heterocycles containing C$\mathrm{N}$ bonds. Such compounds potentially contribute to the observed signals in our chromatograms. However, this would have to be confirmed through the measurement of reference compounds.

A prominent example of a compound eluting during this specific retention period is a compound with $m / z$ 186 eluting at 10.9 min retention time and strongly absorbing at a wavelength of $350 \mathrm{~nm}$. The even $\mathrm{m} / \mathrm{z}$ ratio of this signal indicates that the corresponding protonated molecular ion contains an odd number of nitrogen atoms. Additionally, the MS/MS of this compound shows the loss of a neutral compound with a mass of 27 Dalton, likely corresponding to hydrogen cyanide $(\mathrm{HCN})$. However, it is not possible to elucidate structural information from this data except for the presence of a functional group containing a C-N bond.

Furthermore, esterification or other reactions increasing the molecular weight and lowering the polarity potentially occur in the reaction mixture. Formic acid, which is produced during the formation of IM, is capable of producing formic acid esters and formamides by reacting with alcohols and (secondary) amines present in the reaction mixture, respectively. A compound with $m / z 219$ eluting at a retention time of $10.6 \mathrm{~min}$ absorbs at $280 \mathrm{~nm}$. The MS/MS of this compound reveals fragments of $\mathrm{m} / z 191$ and $\mathrm{m} / z$ 135, potentially corresponding to neutral losses of $\mathrm{CO}$ and $\mathrm{C}_{3} \mathrm{O}_{3}$, respectively. Additionally, the UV absorbance at $280 \mathrm{~nm}$ hints towards a structure similar to BI. Based on these observations a mixed diamid structure is tentatively suggested for this compound (see MS/MS in Fig. 6). However, it cannot be

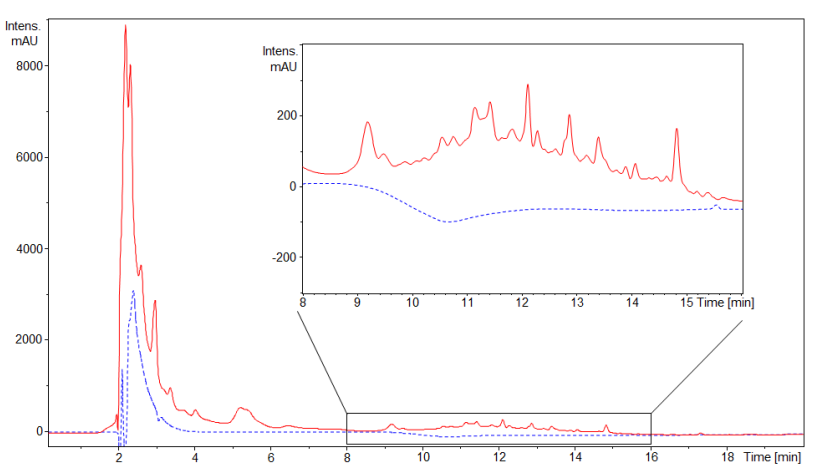

Fig. 5. Temporal evolution of relatively non-polar products in a Gly/AS mixture (1.5 M Gly, 3 M AS). The blue (dotted) chromatogram was recorded immediately after mixing and the red (solid) chromatogram $116.05 \mathrm{~h}$ after mixing (sum of absorbances at wavelengths between 350 and $400 \mathrm{~nm}$ ).

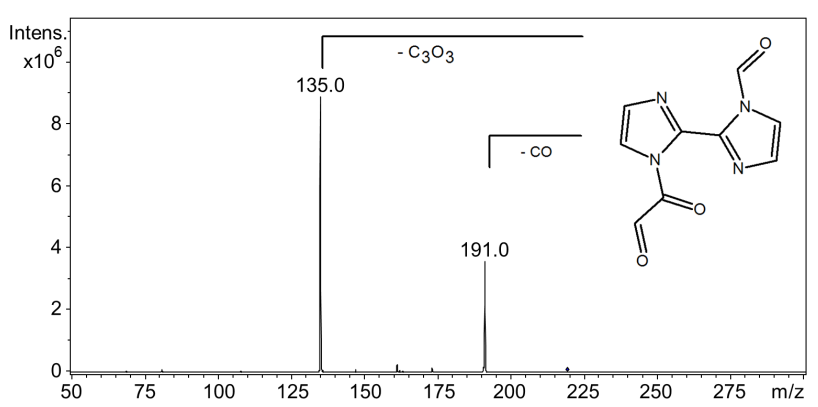

Fig. 6. MS/MS of a compound with $\mathrm{m} / \mathrm{z} 219$ eluting at $10.6 \mathrm{~min}$ retention time. Tentative structure and neutral losses are shown.

ruled out that other structures might show the same fragmentation pattern. The loss of 84 dalton might also correspond to a fragment with the sum formula $\mathrm{C}_{3} \mathrm{H}_{4} \mathrm{~N}_{2} \mathrm{O}$ or $\mathrm{C}_{3} \mathrm{H}_{2} \mathrm{NO}_{2}$. High resolution mass spectrometry should be applied in future studies to reveal the sum formula of those fragments.

The production rates of these compounds seem to be small as they only appear in detectable amounts after several hours after mixing of Gly and AS. However, the variety of potential products including non-imidazole compounds containing $\mathrm{C}$ $\mathrm{N}$ bonds, formamides or formic acid esters in sum could contribute to a considerable amount of the light-absorbing material formed in the Gly/AS mixtures. This demonstrates the complexity of aqueous phase chemistry even in the relatively simple mixture of glyoxal and ammonium sulfate. In the ambient atmosphere the number of potential reaction partners is much higher and an identification of appropriate tracer compounds is necessary to estimate the organic carbon production or the impact on aerosol optical properties from distinct precursors.

Interestingly, the low polarity products absorbing at wavelengths between 350 and $400 \mathrm{~nm}$ might explain the gap Yu et al. (2011) found between known contributors to the $350 \mathrm{~nm}$ 
absorption band and the actual measured absorption in glyoxal/ammonium sulfate solutions. However, due to the lack of appropriate reference compounds a quantitative statement cannot be made at this point.

\subsection{Implications for light-absorbing material from glyoxal in SOA}

The major contributors to light-absorbing material from glyoxal in SOA were identified in recent studies (Galloway et al., 2009; Yu et al., 2011) and extended in this work. The formation of imidazoles including IM, (H)IC and BI strongly depends on the $\mathrm{pH}$ value and the concentrations of glyoxal and ammonium ions, or ammonia respectively (Noziere et al., 2009; Yu et al., 2011; this work). The conditions investigated in the recent studies focused on conditions relevant for aerosols over North America or Europe. However, the formation of imidazoles under these conditions was reported to be of minor importance (Galloway et al., 2009; Ervens and Volkamer, 2010; Yu et al., 2011; Trainic et al., 2011, 2012). This study adds to this point of view, since all additionally identified products were produced in even smaller amounts as the previously reported products.

However, there are regions in the world where SOA formation or changes in aerosol optical properties from nitrogencontaining oligomers of glyoxal might be more important. As discussed above imidazole formation from glyoxal and ammonia in aerosols should be favored in regions with aerosols exhibiting more alkaline $\mathrm{pH}$ values and higher ammonium ion concentrations. Therefore, regions such as northern India are of special interest. Due to regional soil characteristics mineral dust particles in extended Indian regions are alkaline in nature (e.g. Kulshrestha et al., 1998; Parashar et al., 2001). Recent studies also revealed high emissions of ammonia from lifestock waste, its application in agriculture and the application of inorganic fertilizers (Clarisse et al., 2009). As a consequence, certain organic multiphase processes, e.g. the uptake and further reactions of organics and ammonia leading to secondary light-absorbing products (formation of brown carbon), can be expected to be strongly enhanced. Therefore, dedicated experimental studies under such conditions and ambient measurements in India would enable a much better understanding of the regional SOA formation and aging.

Additionally, the identification of $\mathrm{BI}$ as a product in aqueous aerosol mimics containing glyoxal and ammonium sulfate brings up another interesting aspect in connection to light-absorbing material in atmospheric aerosols. 2,2'biimidazole and other bicyclic heteroaromatic compounds are long known to act as bi- or multidentate ligands in the formation of transition metal complexes (e.g. Holmes et al., 1961; Chiswell et al., 1964). Complexes formed in these reactions are generally colored (i.e. red-shifted absorption behavior relative to the parent compounds). Therefore, bicyclic imidazoles acting as bidentate chelating ligands of transition metals (for example in combustion aerosols) might enhance their impact on aerosol optical properties on a regional scale. However, such complexes could also hinder the correct quantification of imidazoles in atmospheric aerosols with common analytical techniques involving UV-Vis spectrometric or mass spectrometric detection.

\section{Conclusions}

The spectrum of products formed in mixtures containing glyoxal and ammonium sulfate was extended in this work. The major reaction products, monocyclic imidazoles, including imidazole, imidazole-2-carboxaldehyde and their N-glyoxal substituted analogs, as well as formic acid, were identified in recent studies (De Haan et al., 2009b, 2011; Galloway et al., 2009; Yu et al., 2011). We report the formation of 2,2'biimidazole and confirm it as a major contributor to the absorption band at $280 \mathrm{~nm}$ measured in Gly/AS mixtures. The production rates of 2,2'-biimidazole are approximately two orders of magnitude smaller than for major reaction products. However, its molar absorptivity at $280 \mathrm{~nm}$ is two orders of magnitude higher than for imidazole-2-carboxaldehyde. This demonstrates the necessity of the molecular identification of products of the reactions in the Gly/AS system at trace levels to enable a better understanding of the observed absorbance features. Very recently, the formation of a product absorbing at a wavelength of $290 \mathrm{~nm}$ was observed in chamber experiments on AS seed particles affecting the radiative properties of the product aerosols by Trainic et al. (2011). Very likely 2,2'-biimidazole contributes significantly to this absorption behavior. Additionally, we report the formation of lower polarity products in Gly/AS mixtures, likely also containing C$\mathrm{N}$ bonds and at least partly having structural similarity to imidazoles. Formamides and formic acid esters of imidazoles potentially explain some of the observed signals, which were not previously reported. Most of these lower polarity products absorb light at near visible wavelengths and thus potentially contribute to the light-absorbing material formed in the Gly/AS mixtures.

As pointed out by Shapiro et al. (2009) and Yu et al. (2011) all those products mentioned before do not contribute substantially to SOA mass. However, we were able to demonstrate that even non-major reaction products in Gly/AS mixtures can be major contributors to the observed absorbance behavior. Therefore, due to the high absorption coefficients of some nitrogen-containing reaction products, an important influence on the optical and radiative properties of ambient aerosols cannot be excluded. Especially in regions with conditions potentially favoring the formation of imidazoles, i.e. a higher $\mathrm{pH}$ value and high ammonium ion concentrations in aerosols (e.g. reported by Kulshrestha et al. (1998) and Parashar et al. (2001) for northern India), this influence could be very strong. 
Additionally, the absorption characteristics of aerosols containing imidazoles, especially bicyclic imidazoles, and transition metals (e.g. iron, copper or manganese in urban and combustion aerosols as reported by See et al., 2006) are potentially influenced by the formation of colored transition metal complexes. 2,2'-biimidazole is known to act as a chelating bidentate ligand in metal complex formation (Holmes et al., 1961). Depending on the respective stability constants and concentrations, those complexes might not only influence the optical properties of the aerosols but also have to be considered as a source of negative artifacts for a potential quantification of imidazoles in ambient aerosols.

\section{Supplementary material related to this article is available online at: http://www.atmos-chem-phys.net/12/ 6323/2012/acp-12-6323-2012-supplement.pdf.}

Acknowledgements. This work was supported by the EC project POLYSOA (Polymers in secondary organic aerosols) and the EU-IP EUCAARI (European Integrated project on Aerosol Cloud Climate and Air Quality Interactions). The authors thank the German Research Foundation (DFG: Deutsche Forschungsgemeinschaft) for their financial support within the Research Training Group 826: Trace Analysis of Elemental Species: Development of Methods and Applications. The authors acknowledge Barbara Nozière and the anonymous referees for their valuable comments, which helped improving the quality of this manuscript.

Edited by: Y. Rudich

\section{References}

Altieri, K. E., Seitzinger, S. P., Carlton, A. G., Turpin, B. J., Klein, G. C., and Marshall, A. G.: Oligomers formed through in-cloud methylglyoxal reactions: Chemical composition, properties, and mechanisms investigated by ultra-high resolution FT-ICR mass spectrometry, Atmos. Environ., 42, 1476-1490, 2008.

Bones, D. L., Henricksen, D. K., Mang, S. A., Gonsior, M., Bateman, A. P., Nguyen, T. B., Cooper, W. J., and Nizkorodov, S. A.: Appearance of strong absorbers and fluorophores in limoneneO3 secondary organic aerosol due to NH4+-mediated chemical aging over long time scales, J. Geophys. Res., 115, D05023, doi:10.1029/2009JD012864, 2010.

Carlton, A. G., Turpin, B. J., Altieri, K. E., Seitzinger, S., Reff, A., Lim, H. J., and Ervens, B.: Atmospheric oxalic acid and SOA production from glyoxal: Results of aqueous photooxidation experiments, Atmos. Environ., 41, 7588-7602, 2007.

Chiswell, B., Lions, F., and Morris, B. S.: Bidentate chelate compounds. III. Metal complexes of some pyridyl-imidazole derivatives, Inorg. Chem., 3, 110-114, 1964.

Cho, J. R., Cho, S. G., Goh, E. M., and Kim, J. K: Preparation method of 2,2'-bi-1H-imidazole using glyoxal and an ammonium salt, United States Patent, 6713631, 2003.
Clarisse, L., Clerbaux, C., Dentener, F., Hurtmans, D., and Coheur, F.: Global ammonia distribution derived from infrared satellite observations, Nat. Geosci., 2, 479-483, doi:10.1038/ngeo551, 2009.

Debus, H.: Über die Einwirkung des Ammoniaks auf Glyoxal, Liebigs Ann. Chem., 107, 199-208, 1858.

De Haan, D. O., Corrigan, A. L., Smith, K. W., Stroik, D. R., Turley, J. J., Lee, F. E., Tolbert, M. A., Jimenez, J. L., Cordova, K. E., and Ferrell, G. R.: Secondary organic aerosol-forming reactions of glyoxal with amino acids, Environ. Sci. Technol., 43, 28182824, 2009a.

De Haan, D. O., Tolbert, M. A., and Jimenez, J. L.: Atmospheric condensed-phase reactions of glyoxal with methylamine, Geophys. Res. Lett., 36, L11819, doi:10.1029/2009GL037441, 2009b.

De Haan, D. O., Hawkins, L. N., Kononenko, J. A., Turley, J. J., Corrigan, A. L., Tolbert, M. A., and Jimenez, J. L.: Formation of Nitrogen-Containing Oligomers by Methylglyoxal and Amines in Simulated Evaporating Cloud Droplets, Environ. Sci. Technol., 45, 984-991, 2011.

Ervens, B., Turpin, B. J., and Weber, R. J.: Secondary organic aerosol formation in cloud droplets and aqueous particles (aqSOA): a review of laboratory, field and model studies, Atmos. Chem. Phys., 11, 11069-11102, doi:10.5194/acp-1111069-2011, 2011.

Fieselmann, B. F., Hendrickson, D. N., and Stucky, G. D: Synthesis, electron paramagnetic resonance, and magnetic studies of binuclear bis $\left(\eta^{5}\right.$-cyclopentadienyl)titanium(III) compounds with bridging pyrazolate, biimidazolate, and bibenzimidazolate anions, Inorg. Chem., 17, 2078-2084, 1978.

Galloway, M. M., Chhabra, P. S., Chan, A. W. H., Surratt, J. D., Flagan, R. C., Seinfeld, J. H., and Keutsch, F. N.: Glyoxal uptake on ammonium sulphate seed aerosol: reaction products and reversibility of uptake under dark and irradiated conditions, Atmos. Chem. Phys., 9, 3331-3345, doi:10.5194/acp-9-3331-2009, 2009.

Hastings, W. P., Koehler, C. A., Bailey, E. L., and De Haan, D. O.: Secondary organic aerosol formation by glyoxal hydration and oligomer formation: Humidity effects and equilibrium shifts during analysis, Environ. Sci. Technol., 39, 22, 8728-8735, 2005.

Holmes, F., Jones, K. M., and Torrible, E. G.: Complex-forming agents similar to 2,2'-bipyridyl. Part I. Some Ligands containing imidazole, J. Chem. Soc., 4790-4794, 1961.

Hallquist, M., Wenger, J. C., Baltensperger, U., Rudich, Y., Simpson, D., Claeys, M., Dommen, J., Donahue, N. M., George, C., Goldstein, A. H., Hamilton, J. F., Herrmann, H., Hoffmann, T., Iinuma, Y., Jang, M., Jenkin, M. E., Jimenez, J. L., KiendlerScharr, A., Maenhaut, W., McFiggans, G., Mentel, T. F., Monod, A., Prevot, A. S. H., Seinfeld, J. H., Surratt, J. D., Szmigielski, R., and Wildt, J.: The formation, properties and impact of secondary organic aerosol: current and emerging issues, Atmos. Chem. Phys., 9, 5155-5236, doi:10.5194/acp-9-5155-2009, 2009.

Jimenez, J. L., Canagaratna, M. R., Donahue, N. M., Prevot, A. S. H., Zhang, Q., Kroll, J. H., DeCarlo, P. F., Allan, J. D., Coe, H., Ng, N. L., Aiken, A. C., Docherty, K. S., Ulbrich, I. M., Grieshop, A. P., Robinson, A. L., Duplissy, J., Smith, J. D., Wilson, K. R., Lanz, V. A., Hueglin, C., Sun, Y. L., Tian, J., Laaksonen, A., Raatikainen, T., Rautiainen, J., Vaattovaara, P., Ehn, M., Kulmala, M., Tomlinson, J. M., Collins, D. R., Cubison, M. 
J., Dunlea, E. J., Huffman, J. A., Onasch, T. B., Alfarra, M. R., Williams, P. I., Bower, K., Kondo, Y., Schneider, J., Drewnick, F., Borrmann, S., Weimer, S., Demerjian, K., Salcedo, D., Cottrell, L., Griffin, R., Takami, A., Miyoshi, T., Hatakeyama, S., Shimono, A., Sun, J. Y., Zhang, Y. M., Dzepina, K., Kimmel, J. R., Sueper, D., Jayne, J. T., Herndon, S. C., Trimborn, A. M., Williams, L. R., Wood, E. C., Middlebrook, A. M., Kolb, C. E., Baltensperger, U., and Worsnop, D. R.: Evolution of Organic Aerosols in the Atmosphere, Science, 326, 1525-1529, 2009.

Kalberer, M., Paulsen, D., Sax, M., Steinbacher, M., Dommen, J., Prevot, A. S. H., Fisseha, R., Weingartner, E., Frankevich, V., Zenobi, R., and Baltensperger, U.: Identification of polymers as major components of atmospheric organic aerosols, Science, 303, 1659-1662, 2004.

Kua, J., Krizner H. E., and De Haan, D. O.: Thermodynamics and Kinetics of Imidazole Formation from Glyoxal, Methylamine, and Formaldehyde: A Computational Study, J. Phys. Chem. A, 115, 1667-1675, 2011.

Kulshrestha, U. C., Saxena, A., Kumar, N., Kumari, K. M., and Srivastava, S. S.: Chemical composition and association of sizedifferentiated aerosols at a suburban site in a semi-arid tract of India, J. Atmos. Chem., 29, 109-118, 1998.

Liggio, J., Li, S. M., and McLaren, R.: Heterogeneous reactions of glyoxal on particulate matter: Identification of acetals and sulfate esters, Environ. Sci. Technol., 39, 1532-1541, 2005a.

Liggio, J., Li, S. M., and McLaren, R.: Reactive uptake of glyoxal by particulate matter, J. Geophys. Res. Atmos., 110, D10304, doi:10.1029/2004JD005113, 2005b.

Lim, Y. B., Tan, Y., Perri, M. J., Seitzinger, S. P., and Turpin, B. J.: Aqueous chemistry and its role in secondary organic aerosol (SOA) formation, Atmos. Chem. Phys., 10 1052110539, doi:10.5194/acp-10-10521-2010, 2010.

Loeffler, K. W., Koehler, C. A., Paul, N. M., and De Haan, D. O.: Oligomer formation in evaporating aqueous glyoxal and methyl glyoxal solutions, Environ. Sci. Technol., 40, 6318-6323, 2006.

Mao, F., Mano, N., and Heller, A.: Long tethers binding redox centers to polymer backbones enhance electron transport in enzyme "wiring" hydrogels, J. Am. Chem. Soc., 125, 4951-4957, 2003.

Noziere, B., Dziedzic, P., and Cordova, A.: Products and kinetics of the liquid-phase reaction of glyoxal catalyzed by ammonium ions (NH4+), J. Phys. Chem. A, 113, 231-237, 2009.

Odum, J. R., Hoffmann, T., Bowman, F., Collins, D., Flagan, R. C., and Seinfeld, J. H.: Gas/particle partitioning and secondary organic aerosol yields, Environ. Sci. Technol., 30, 2580-2585, 1996.

Pankow, J. F.: An absorption model of the gas/aerosol partitioning involved in the formation of secondary organic aerosol, Atmos. Environ., 28, 189-193, 1994.

Parashar, D. C., Kulshrestha, U. C., and Jain, M.: Precipitation and aerosol studies in India, Environ. Monit. Assess., 66, 47-61, 2001.

Sareen, N., Schwier, A. N., Shapiro, E. L., Mitroo, D., and McNeill, V. F.: Secondary organic material formed by methylglyoxal in aqueous aerosol mimics, Atmos. Chem. Phys., 10, 997-1016, doi:10.5194/acp-10-997-2010, 2010.

Schwier, A. N., Sareen, N., Mitroo, D., Shapiro, E. L., and McNeill, V. F.: Glyoxal-Methylglyoxal Cross-Reactions in Secondary Organic Aerosol Formation, Environ. Sci. Technol., 44, 6174-6182, 2010 .
See, S. W., Wang, Y. H., and Balasubramanian, R.: Contrasting reactive oxygen species and transition metal concentrations in combustion aerosols, Environ. Res., 103, 317-324, 2007.

Seinfeld, J. H. and Pandis, S. N.: Atmospheric chemistry and physics: From air pollution to climate change, 2nd Edn., Wiley, Hoboken, 2006.

Shapiro, E. L., Szprengiel, J., Sareen, N., Jen, C. N., Giordano, M. R., and McNeill, V. F.: Light-absorbing secondary organic material formed by glyoxal in aqueous aerosol mimics, Atmos. Chem. Phys., 9, 2289-2300, doi:10.5194/acp-9-2289-2009, 2009.

Surratt, J. D., Kroll, J. H., Kleindienst, T., E., Edney, E. O., Claeys, M., Sorooshian, A., Ng, N. L., Offenberg, J. H., Lewandowski, M., Jaoui, M., Flagan, R., and Seinfeld, J. H.: Evidence for organosulfates in secondary organic aerosol, Environ. Sci. Technol., 41, 517-527, doi:10.1021/es062081q, 2007.

Surratt, J. D., Gomez-Gonzalez, Y., Chan, A. W. H., Vermeylen, R., Shahgholi, M., Kleindienst, T. E., Edney, E. O., Offenberg, J. H., Lewandowski, M., Jaoui, M., Maenhaut, W., Claeys, M., Flagan, R. C., and Seinfeld, J. H.: Organosulfate formation in biogenic secondary organic aerosol, J. Phys. Chem. A, 112, 8345-8378, doi:10.1021/jp802310p, 2008.

Tan, Y., Perri, M. J., Seitzinger S. P., and Turpin, B. J.: Effects of precursor concentration and acidic sulfate in aqueous glyoxal-OH radical oxidation and implications for secondary organic aerosol, Environ. Sci. Technol., 43, 8105-8112, doi:10.1021/es901742f, 2009.

Tan, Y., Carlton, A. G., Seitzinger, S. P., and Turpin, B. J.: SOA from methylglyoxal in clouds and wet aerosols: Measurement and prediction of key products, Atmos. Environ., 44, 5218-5226, 2010.

Trainic, M., Riziq, A. A., Lavi, A., Flores, J. M., and Rudich, Y.: The optical, physical and chemical properties of the products of glyoxal uptake on ammonium sulfate seed aerosols, Atmos. Chem. Phys., 11, 9697-9707, doi:10.5194/acp-11-9697-2011, 2011.

Trainic, M., Riziq, A. A., Lavi, A., and Rudich, Y.: The role of interfacial water in the heterogeneous uptake of glyoxal by mixed glycine and ammonium sulfate aerosols, J. Phys. Chem. A., 116, 5948-5957, doi:10.1021/jp2104837, 2012.

Yasmeen, F., Sauret, N., Gal, J. -F, Maria, P.-C, Massi, L., Maenhaut, W., and Claeys, M.: Characterization of oligomers from methylglyoxal under dark conditions: a pathway to produce secondary organic aerosol through cloud processing during nighttime, Atmos. Chem. Phys., 10, 3803-3812, doi:10.5194/acp-103803-2010, 2010.

Yu, G., Bayer A. R., Galloway, M. M., Korshavn, K. J., Fry, C. G., and Keutsch, F. N.: Glyoxal in Aqueous Ammonium Sulfate Solutions: Products, Kinetics and Hydration Effects, Environ. Sci. Technol., 45, 6336-6342, 2011.

Zhao, J., Levitt, N. P., Zhang, R. Y., and Chen, J. M.: Heterogeneous reactions of methylglyoxal in acidic media: Implications for secondary organic aerosol formation, Environ. Sci. Technol., 40, 7682-7687, 2006.

Zhang, Q., Jimenez, J. L., Canagaratna, M. R., Allan, J. D., Coe, H., Ulbrich, I., Alfarra, M. R., Takami, A., Middlebrook, A. M., Sun, Y. L., Dzepina, K., Dunlea, E., Docherty, K., DeCarlo, P. F., Salcedo, D., Onasch, T., Jayne, J. T., Miyoshi, T., Shimono, A., Hatakeyama, S., Takegawa, N., Kondo, Y., Schneider, J., Drewnick, F., Borrmann, S., Weimer, S., Demerjian, K., 
Williams, P., Bower, K., Bahreini, R., Cottrell, L., Griffin, R. J., Rautiainen, J., Sun, J. Y., Zhang, Y. M., and Worsnop, D. R.: Ubiquity and dominance of oxygenated speciesin organic aerosols in anthropogenically-influenced Northern Hemisphere midlatitudes, Geophys. Res. Lett., 34, L13801, doi:10.1029/2007GL029979, 2007. 